\title{
APLICAÇÃO DOS SISTEMAS DE INFORMAÇÃO GEOGRÁFICA NO TURISMO*
}

\author{
Paulo Rocha E Sousa ${ }^{1}$
}

Sílvia Brito Fernandes²

\begin{abstract}
Resumo - Com o objectivo de incrementar as relações entre os agentes socioeconómicos envolvidos no sector turístico e seus clientes, mostrando os produtos e serviços que oferecem, harmonizados com descrições histórico-culturais locais, pretende-se ensaiar a concepção de um sistema de informação com componente geográfica (SIG) para aplicação no turismo. O sistema deve permitir a integração de vários serviços de informação, acessíveis através de diferentes plataformas tecnológicas, para que os agentes possam estabelecer relações formais e informais entre si, utilizando as tecnologias de comunicação ao seu alcance. A referenciação geográfica dos locais é integrada com informação adicional específica, de forma a permitir uma maior percepção dos recursos existentes. Para se consolidar junto do público-alvo, designadamente turistas e visitantes, o sistema deve ser enriquecido com conteúdos multimédia e de carácter geográfico, histórico, cultural, etnográfico com o objectivo de conquistar a sua utilização.

A definição de regras de acesso e construção de conteúdos, incluindo a consideração de critérios de qualidade e de perfis comportamentais ao longo do tempo, são elementos enriquecedores para o SIG. A disponibilização destes conteúdos deve ser realizada de acordo com o tipo e localização da plataforma de acesso como meio de potenciar a sua utilização e a realização económica dos agentes envolvidos. Aspectos relevantes a explorar são, por um lado, a importância do sistema para o turismo na medida em que pode orientar estratégias de ocupação do território e de desenvolvimento sustentado e, por outro lado, a criação de novos negócios e serviços online mais seguros e concebidos de acordo com os padrões definidos no sistema. Estes padrões devem ser adequados às estratégias e políticas definidas para o sector a nível nacional e regional, pois o público-alvo procura encontrar informações úteis sobre as várias regiões para tomar a melhor decisão. Com o amadurecimento do sistema, outros sectores de actividade poderão ser objecto da expansão do mesmo.
\end{abstract}

Palavras-chave: Turismo, sistema de informação, plataforma tecnológica, sistema de informação geográfica.

* Recebido: 20/01/2007. Revisto: 7/09/2007; 05/12/07. Aceite: 19/12/2007.

1 Analista Programador - Núcleo de Sistemas de Informação. Centro Distrital de Segurança Social de Faro. Email: Paulo.j.sousa@seg-social.pt

2 Professora Auxiliar, Faculdade de Economia - Universidade do Algarve. E-mail: sfernan@ualg.pt 


\begin{abstract}
APPLYING GEOGRAPHICAL INFORMATION SYSTEMS TO THE TOURISM SECTOR. With the aim of enabling the stakeholders involved in the tourism business to improve their relationships with their clients, by making it possible for them to present the products and services on offer within their historical and cultural context, this article addresses the issue of designing a geographic information system (GIS) to be used by the tourism sector. Such a system should allow for the integration of a variety of services, accessible through various technology platforms, thus enabling agents to interact both formally and informally through the use of the communication technologies available to them. The geographical referencing of the various places and tourist sites should be complemented by specific additional information, in order to allow for a better perception of the existing resources. In order to reach a wide public, especially tourists and residents, the system should be enhanced with multimedia contents, as well as with geographic, historical, cultural and ethnographic information.

Setting adequate rules and procedures for both accessing and changing the contents of the information system, namely through quality criteria and the creation of user profiles, can contribute significantly to enriching the GIS. The specific way in which the contents are made accessible to the public should take into account the characteristics and physical location of the technology platform that is used, so as to enhance the system's use and the economic returns to the agents involved. Other relevant issues addressed in this article include, on the one hand, the importance of these systems for the tourism sector, insofar as they can contribute decisively to setting strategic guidelines in terms of land use and sustainable territorial development; and, on the other hand, the setting up of new, and more secure, online businesses and services that comply with the standards and characteristics of the GIS. The latter should be designed in accordance with the regional and national strategies and policies adopted in the tourism sector, since the public expects to be able to find useful information about the various regions in order to make an informed decision. As the system gradually matures, it can then be expanded to include other activity sectors.
\end{abstract}

Key-words: Tourism, information system, technology platform, geographic information system.

Résumé - APLICATION AU TOURISME DES SYSTÈMES D'INFORMATION GÉOGRAPHIQUE. Pour faciliter les rapports entre les agents et les clients du secteur socio-économique du tourisme, on propose un système d'information géographique (SIG), comprenant à la fois les produits et services offerts et des descriptions historico-culturelles des lieux visités. Ce système intègre divers sub-systèmes, accessibles à partir de plusieurs plateformes technologiques, afin que les agents puissent établir entre eux des liaisons formelles ou informelles, en utilisant leurs propres technologies de communication. La référenciation géographique des lieux facilite la perception des ressources existantes. Pour attirer le public touristique, ce système est enrichi par des données multimédias sur la géographie, l'histoire et la culture des lieux mentionnés.

Ce SIG comprend la définition de ses règles d'accès et de construction, ainsi que des critères de qualité et de durée. Ces données sont fournies en fonction des divers types de plateformes d'accès. Ce système peut aider à orienter les stratégies d'occupation du territoire et à créer de nouveaux services online plus sûrs. Il devra être adapté aux stratégies définies au niveau national et régional, et poura aussi être adapté à d'autres secteurs d'activité.

Mots-clés: Tourisme, système d'information, plateforme technologique, SIG. 


\section{OS SIG NO APOIO À OFERTA E GESTÃO DO TURISMO}

Milhões de pessoas fazem viagens internacionais todos os anos e muitas outras viajam em negócios ou para se descontraírem dentro do país em que vivem. Para responder às necessidades do crescente número de turistas e visitantes, surgiram os grandes hotéis que começaram por se instalar perto de terminais ferroviários e portos. Em meados do século XX, férias e viagens turísticas tornaram-se parte da cultura do Ocidente e eram acessíveis à maioria das classes sociais. Milhões de famílias ficaram fascinadas com as imagens de lugares exóticos, estimulando o seu desejo de viajar. Surgiram então resorts em todo o mundo para atender às necessidades dos turistas nacionais e internacionais. O turismo envolve assim hotéis, resorts, companhias aéreas, agências de viagens e serviços de apoio aos que viajam.

Por sua vez, dado que os turistas consomem grande quantidade de produtos alimentares e adquirem mercadorias e serviços, várias indústrias não directamente relacionadas com o turismo têm beneficiado do seu crescimento. Daí que actualmente o turismo seja importante para a economia de muitos países, desencadeando um número crescente de empresas relacionadas. A partir da década de 80, surge uma nova consciência (ambiental, cultural e social) a partir do momento em que alguns cientistas e produtores de documentários se interessam pela preservação de florestas tropicais, recifes de corais e suas espécies. A divulgação dessas maravilhas naturais aumentou o interesse do público em visitá-las e surgem novas empresas para dar apoio ao fluxo de visitantes desta nova vertente do "ecoturismo". Uma viagem ecológica deve fornecer informações sobre a cultura e o ambiente a ser visitado, além de orientações sobre vestuário e comportamento apropriados, bem como instruções detalhadas sobre características geográficas, sociais e políticas do local de destino (Wood, 2002; Boyd e Butler, 1996). Deve ainda proporcionar oportunidades de interagir com as pessoas locais e oferecer acomodações que não prejudiquem o ecossistema (Ananthaswamy, 2004).

Estes têm sido também os atributos recentemente procurados pelos turistas portugueses. Correia e Moço (2005), ao analisar as imagens mentais que os turistas formam sobre os destinos, verificam que as componentes natural ${ }^{3}$ e regional ${ }^{4}$ são determinantes, comprovando que os recursos naturais de certos destinos são factores de crescente competitividade. Daí resulta a necessidade de integrar a complexa e variada informação associada e de a referenciar no espaço. Nesse sentido, os sistemas de informação geográfica e a sua integração com a tecnologia multimédia representam um potencial crescente na inventariação de áreas de elevado interesse e na análise integrada de impactos (Millar et al., 1994; Lau e McKercher, 2007). Na era da sociedade da informação, as tecnologias e sistemas de informação têm assumido um papel determinante no desenvolvimento e sucesso das organizações em geral. Estas utilizam tecnologias emergentes de forma a tornarem-se mais competitivas nas suas actividades e serviços. Tais recursos também lhes permitem estabelecer novas formas de interagir com os seus parceiros de negócio. $\mathrm{O}$ acesso à Internet tem permitido a estas organizações manter uma presença no ciberespaço a preços competitivos. Contudo, em muitos casos, essa presença revela apenas o seu portfólio de produtos e serviços e não uma activa plataforma de divulgação, entrega e distribuição. Outras organizações investiram neste tipo

3 Esta componente pode incluir: paisagem, clima, gastronomia, etc.

4 Esta componente pode incluir: acessibilidades, atracções culturais, etc. 
de plataforma, apresentando websites assentes em serviços electrónicos numa tentativa de aumentar a sua penetração no mercado, como é o caso do negócio turístico. Por exemplo, só em 2003 mais de 30\% das vendas online foram geradas em viagens (Hadzic, 2004). O negócio turístico é fortemente influenciado pela difusão das Tecnologias de Informação e Comunicação (TIC), uma vez que é uma actividade intensiva em informação (Poon, 1993).

Os serviços turísticos, dado o seu carácter intangível, não podem ser disponibilizados nem experimentados antes da sua aquisição, pelo que a sua avaliação fica dependente da informação existente nas formas impressa e audio-visual. Um produto turístico de sucesso dependerá de um marketing extensivo e direccionado, que conduza à criação de novos canais de distribuição. As TIC fornecem oportunidades para a expansão do negócio a nível geográfico, operacional e de marketing. As exibições virtuais e fotografias digitais, assentes na natureza multimédia e interactiva da Web, dão uma nova dimensão ao marketing de destinos turísticos (Buhalis, 2003). Um sistema multicanal e multimédia de gestão de destinos serve objectivos, não só de distribuição e planeamento de informação para viagens, como de educação e entretenimento, fundamentais para um desenvolvimento sustentado do turismo. Nesse sentido, Hadzic (2004) defende que cada destino turístico deve ser acedido por meio de um portal Web integrado, em vez de uma fragmentação de páginas Web individuais dos diferentes agentes envolvidos (agências de viagens, operadores turísticos, hotéis, serviços).

Nos sectores de serviços como o turismo, a produção aparece integrada com o consumo, o que reforça o papel activo dos clientes no processo de criação do serviço. A percepção da sua qualidade e valor são factores que afectam a motivação para visitar um destino. Isso requer a educação necessária, que pode ser enriquecida pela informação digitalizada disponível online. Os interessados podem ficar informados sobre destinos que não imaginavam antes que existissem. Por sua vez, um sistema de informação integrado fomenta relações de partilha de conhecimento que desempenham um papel fulcral na gestão das relações com o cliente $(C R M)^{5}$. Esta função, junto com a definição de novos conceitos, contribui para o desenvolvimento de bases de dados inteligentes que vão "conhecendo" comportamentos e perfis de preferência dos utilizadores. Também "se apercebem" de como as orientações do sistema podem encorajar determinados comportamentos e escolhas. Assim, o sistema mudará as suas características dinâmica e automaticamente consoante as necessidades do utilizador e menor será o esforço requerido por parte deste.

\section{A UTILIZAÇÃO DOS SIG NO APOIO À PROCURA TURÍSTICA}

Os SIG constituem um poderoso conjunto de ferramentas de recolha, armazenamento, actualização, gestão, análise e exibição de dados espaciais. A incorporação desta tecnologia pode contribuir para melhorar os serviços oferecidos no mercado turístico, pois assenta na capacidade de fazer chegar informação a diferentes agentes, incluindo a comunidade. Uma grande parte desta informação é inerentemente espacial,

5 Customer Relationship Management - gestão das relações com o cliente (envolvendo comportamentos, perfis de escolha e satisfação, expectativas, atitudes). 
indicando onde se encontram os recursos turísticos, quão extensivos eles são e a intensidade com que são utilizados. Isto sugere que os SIG podem constituir uma ferramenta útil e eficaz no planeamento da actividade turística. As mudanças que ocorrem no turismo, a competição entre produtos e destinos turísticos e as alterações nos comportamentos dos turistas são vectores que terão de ser geridos do ponto de vista do planeamento, estratégia e desenvolvimento de espaços turísticos (Colak e Aydinoglu, 2006).

Um turista, ao visitar uma dada região, deseja descobrir os recantos e paisagens, saborear a gastronomia local, praticar alguma actividade lúdica ou conhecer os usos e costumes, isto é, um pouco da história e cultura do povo residente. Se o turista tiver um acesso fácil a esta diversidade de informação a partir da Internet, do televisor de seu quarto de hotel, de quiosques especializados, ou até de um sistema instalado no automóvel que aluga ou no seu próprio telemóvel, o leque de possibilidades é um convite a interagir mais de perto com a realidade da região que escolheu para o seu lazer. Um sistema de informação (SI) orientado para esta interacção múltipla e coadjuvado pela dimensão de referenciação geográfica torna-se relevante pela inovação e competitividade que suscita. Uma competitividade pela cooperação pode favorecer o enriquecimento das relações entre os vários agentes socio-económicos envolvidos no sector turístico e destes com os utilizadores, mostrando os produtos e serviços que oferecem em cada região (Chen, 2007). Para isso, o sistema deve permitir a integração de vários serviços de informação, acessíveis através de diferentes plataformas tecnológicas, para que os agentes possam estabelecer relações formais e informais entre si utilizando as tecnologias de comunicação ao seu alcance.

$\mathrm{O}$ acesso a dados georeferenciados vem acrescentar valor aos produtos e serviços, assumindo as tecnologias de informação geográfica um papel fundamental na utilização do SI. A referenciação geográfica dos locais é integrada com informação adicional específica, de forma a permitir uma maior percepção dos recursos existentes (HainesYoung et al., 1994). Ao ser enriquecido com conteúdos multimédia e de carácter geográfico, histórico, cultural, etnográfico, entre outros, o sistema tende a reforçar a sua sustentabilidade junto do público-alvo, designadamente turistas e visitantes. Uma das principais dificuldades da actividade turística é a manutenção e actualização rápida de todos estes dados. Itens acerca de belezas geográficas, eventos culturais, hotéis, parques de entretenimento, exposições, festivais e feiras são continuamente compilados por autoridades locais. Os processos usuais de publicação destes dados muitas vezes não respondem às necessidades de selecção, integração ou utilização imediata dos mesmos. São mais frequentemente veiculados através de canais convencionais como panfletos, revistas, brochuras e afins. Tecnologias como a multimédia e os sistemas de informação geográfica constituem um grande potencial no mercado de aplicações no âmbito dos sistemas de gestão turística, na medida em que tornam possível o acesso aos dados em formato electrónico. Os custos em que incorre uma distribuição deste tipo podem ser evitados pela operacionalização de uma base de dados multimédia, gerida localmente e disponível através da Internet aos analistas e programadores de aplicações (Benabdallah e Soltane, 1996).

Por sua vez, a combinação destas tecnologias com o suporte sistémico geográfico permite: dispôr de novas funcionalidades baseadas em dados vectoriais (optimização de caminhos, adjacências, cálculo de proximidades), gerar automaticamente um largo espectro de novas aplicações turísticas baseadas nestas tecnologias e desenvolver uma base 
de dados geográfica distribuída ${ }^{6}$. Assim, a sua integração possibilitará às autoridades locais actualizar os dados de um modo fácil, eficiente e a baixo custo. O quadro seguinte evidencia, em particular, o potencial dos SIG na resolução de problemas inerentes ao negócio turístico.

Quadro I - Potencial dos SIG no apoio do planeamento turístico

Table I - Potential of GIS in support of Tour Planning

\begin{tabular}{ll}
\hline \multicolumn{1}{c}{ Natureza do problema } & \multicolumn{1}{c}{ Aplicação dos SIG } \\
\hline $\begin{array}{l}\text { Os agentes envolvidos nem sempre dispõem dos } \\
\text { tipos de informação necessária a uma visão } \\
\text { consensual e harmonizada. }\end{array}$ & $\begin{array}{l}\text { Os SIG podem ser usados para uma inventariação } \\
\text { sistemática dos recursos turísticos e uma análise } \\
\text { de tendências. }\end{array}$ \\
$\begin{array}{l}\text { Dificuldade em determinar níveis de } \\
\text { desenvolvimento sustentado do turismo devido à } \\
\text { complexidade da definição deste conceito. }\end{array}$ & $\begin{array}{l}\text { Os SIG podem ser usados para monitorizar e } \\
\text { controlar as actividades turísticas. Ao integrarem } \\
\text { dados turísticos, ambientais, culturais e socio- } \\
\text { económicos os SIG facilitam o controlo de }\end{array}$ \\
$\begin{array}{l}\text { indicadores de desenvolvimento sustentado. } \\
\text { Gerir e controlar o desenvolvimento tendo em } \\
\text { conta capacidades, usos e competências. }\end{array}$ & $\begin{array}{l}\text { Os SIG podem ser usados para identificar } \\
\text { localizações adequadas e convenientes e áreas de } \\
\text { conflito e de complementaridade. }\end{array}$ \\
$\begin{array}{l}\text { O turismo é um sector com impactos que não } \\
\text { podem ser facilmente revertidos. }\end{array}$ & $\begin{array}{l}\text { Os SIG podem ser usados para simular resultados } \\
\text { espaciais dos desenvolvimentos propostos e } \\
\text { sensibilizar os agentes para as externalidades de } \\
\text { suas acções. }\end{array}$ \\
$\begin{array}{l}\text { Os SIG permitem a integração de dados } \\
\text { representativos do capital socio-económico e }\end{array}$ \\
$\begin{array}{l}\text { mudanças que podem produzir conflitos intra e } \\
\text { inter-sectoriais que podem afectar os seus } \\
\text { recursos. }\end{array}$ & $\begin{array}{l}\text { ambiental num dado contexto espacial. Os SIG } \\
\text { assumem um papel preponderante no planeamento } \\
\text { estratégico espacial. }\end{array}$ \\
$\begin{array}{l}\text { Excesso de níveis de direcção e controlo no } \\
\text { desenvolvimento do turismo, o que conduz a } \\
\text { desacordos. }\end{array}$ & $\begin{array}{l}\text { As funções dos SIG de apoio à decisão permitem } \\
\text { argumentos mais informados, o que aumenta o } \\
\text { compromisso e a resolução. Isso pressupõe uma } \\
\text { abordagem coerente de planeamento e controlo. }\end{array}$ \\
\hline
\end{tabular}

Fontes: Bahaire e Elliot-White, 1999 e própria

Vários estudos têm revelado uma utilidade crescente da aplicação dos SIG no planeamento turístico e no levantamento dos melhores locais para seu desenvolvimento. Gunn (1994) usou-os para identificar as áreas de maior potencial turístico, baseadas nos seus recursos naturais e culturais. Os SIG serviam como meio de consolidação da informação geográfica de forma a complementar a análise e o planeamento (Elliot-White e Finn, 1998). Também Boyd e Butler (1996) usaram estes sistemas para inventariação, cartografia e identificação de áreas de influência humana. Muitas vezes, as infra-estru-

6 SGBD (sistemas de gestão de bases de dados) multi-utilizador com extensões espaciais são: ORACLE, MySQL, SQL Server, POSTGRES. 
turas são afectadas pelo crescimento turístico o que suscita a pressão de agentes regionais e ambientais. Deste modo, os SIG constituem uma ferramenta eficaz no desenho e monitorização do desenvolvimento turístico (Holm-Pedersen, 1994; Chen, 2007). De seguida, é apresentado o conceito de um sistema de informação integrado para suporte do negócio turístico e da dinâmica dos agentes envolvidos. São descritos os seus objectivos, requisitos tecnológicos e a componente SIG que o pode enriquecer, permitindo aos decisores explorar o potencial da dimensão geográfica dos dados. A informação georeferenciada acrescenta rigor à análise dos projectos que possam deteriorar o ambiente ou os recursos locais, bem como das áreas onde os projectos possam ter uma maior visibilidade $^{7}$ (Selman et al., 1991).

\section{UMA APLICAÇÃO AO NEGÓCIO TURÍSTICO}

A definição de regras de acesso e construção de conteúdos, incluindo a consideração de critérios de qualidade e de perfis comportamentais ao longo do tempo, são elementos enriquecedores para o sistema de informação (SI). Aspectos relevantes a explorar são, por um lado, a importância do sistema para o planeamento do sector, na medida em que pode orientar estratégias de ocupação do território e, por outro, a criação de novos serviços online mais seguros e concebidos de acordo com os padrões definidos no SI. Estes devem ser adequados às estratégias e políticas do sector a nível nacional e regional, pois o público-alvo procura encontrar informações úteis sobre as várias regiões turísticas para tomar a melhor decisão. O sistema proposto envolve vários serviços de informação, acessíveis através de plataformas tecnológicas e interligados num sistema de informação para o turismo. Tais serviços são orientados para o sector turístico, o qual assume um importante peso na economia portuguesa em geral e na da região do Algarve em particular. Podem provir da indústria hoteleira, restauração, operadores turísticos, agências de viagens, rent-a-car's, etc. Estes agentes estabelecem relações económicas formais e informais entre si, utilizando da melhor forma os canais de comunicação ao seu alcance.

\section{Conceito e requisitos do sistema}

O sistema de informação aqui delineado permite estabelecer um meio de comunicação entre dois ou mais agentes, em tempo real, de modo a simplificar os seus contactos e potenciar as suas relações, que se poderão traduzir no crescimento económico de ambos. O sistema permite, igualmente, pesquisar informações e conteúdos de natureza variada que são da responsabilidade dos respectivos agentes. Tais pesquisas poderão ser de carácter geral ou especificar determinado serviço ou produto, agente ou grupo de agentes que coordenam estratégias entre si. As principais capacidades do sistema podem ser traduzidas do seguinte modo:

- um serviço ou produto pode ser pesquisado individualmente ou inserido numa gama de bens de um ou vários agentes;

\footnotetext{
7 Por exemplo, através da topografia digital com a utilização de imagens 3-D.
} 
- um agente pode publicar os seus produtos e serviços prestados, diferenciando-os de acordo com as suas políticas de contratação com clientes e fornecedores;

- um agente pode contactar potenciais novos clientes e fornecedores de um modo rápido, directo e simples;

- um agente tem a possibilidade de estabelecer contacto com os consumidores finais de uma forma igualmente directa, rápida e simples;

- cada agente determina a melhor forma de interacção e posicionamento no sistema de acordo com as opções disponibilizadas pelo mesmo;

- o acesso pode estabelecer-se através da Internet, de postos fixos em locais de elevado interesse turístico, de telemóveis, etc.;

- podem realizar-se negócios online com elevada segurança e de acordo com padrões definidos no sistema.

Esta última capacidade implica a criação de padrões de qualidade na oferta turística. A disponibilização dos conteúdos deve ser realizada de acordo com o tipo e localização da plataforma de acesso, como meio de potenciar a utilização da informação e a realização económica dos agentes envolvidos. Com o amadurecimento do sistema, outros sectores de actividade poderão ser objecto da expansão do mesmo.

\section{Principais requisitos tecnológicos}

A figura 1 ilustra as relações entre as entidades que podem utilizar o sistema de informação. O objectivo é criar e manter os dados actualizados sobre as diversas actividades turísticas e permitir que os interessados estabeleçam relações entre si através de processos criados para o efeito. Seguidamente, descrevem-se as suas componentes:

- Sistema de Informação - constituído por um conjunto de bases de dados e procedimentos sistémicos, concebidos para gerir de forma eficiente a informação aí contida e os conteúdos multimédia associados. Deve manter a informação actualizada sobre a oferta de serviços e produtos destinados ao turismo no território português. Estes são disponibilizados pelos agentes (legalmente constituídos e registados no sistema) a outros agentes envolvidos no negócio turístico e aos consumidores finais (turistas, visitantes e até residentes que desejam informação sobre diversos eventos e locais);

- Componente SIG - a capacidade de disponibilizar muita e variada informação, de classificá-la e geri-la da melhor forma possível determina a escolha das plataformas tecnológicas a implementar. Para esse efeito, muitas vezes é necessário construir soluções eficazes recorrendo a sistemas de informação geográfica (SIG). Estes têm como objectivo a produção de informação georeferenciada, a execução de mapas e saídas gráficas, análises espaciais, entre outras funções. Têm um papel fundamental na definição dos conteúdos a exibir, orientados para a localização do emissor do pedido de informação. O SIG é usado aqui para gerar mapas com os percursos de estrada, circuitos de caminhada, passeios de jipe pela serra, etc. As vantagens de utilização de mapas digitais são consideráveis (poupança do espaço de armazenamento, não danificação dos mesmos, comparando com os mapas em papel, e menores custos de actualização); 
- Agente - através de um operador de Internet, e respeitando alguns requisitos de segurança, o agente estará em contacto com os seus clientes, fornecedores e outros agentes em tempo real, o que lhe permite coordenar de uma forma eficaz os seus negócios. O sistema permite ao agente configurar cada serviço ou produto do seu portfólio de acordo com as regras estabelecidas para cada tipo de cliente. Este terá acesso a uma área reservada para si pelo agente, onde pode encontrar informação sobre as características do serviço, catálogo, preços, descontos e outras condições. Esta capacidade permite a criação de nichos de mercados para públicos com determinados perfis. $\mathrm{O}$ agente pode sempre disponibilizar informações de seus serviços e produtos para pesquisas sem restrições de acessos;

- Postos Fixos - a sua localização é especificada em função de alguns parâmetros e têm por objectivo disponibilizar informações (de carácter histórico, cultural, social, etc.) sobre a área turística onde estão implantados, bem como sobre os bens e serviços dos agentes da mesma. Os quiosques multimédia e os multibancos ${ }^{8}$ (se derem acesso ao software com a informação e opções do sistema) constituem exemplos de postos fixos;

- $\quad P D A /$ telemóvel - têm por referência a sua localização geográfica e disponibilizam o mesmo tipo de conteúdos, tratados e adaptados para o devido efeito. O turista pode obter informação do sistema através de um telemóvel ou de um computador portátil com que acede à Internet em qualquer local (hotel, barco, carro, aeroporto, restaurante, etc), utilizando um serviço específico fornecido pelo operador que disponibilize dados contidos no sistema. Por exemplo, o turista chega ao aeroporto e aluga um carro que, se estiver equipado com $P D A^{9}$ e $G P S^{10}$, pode passar as suas coordenadas exactas de posicionamento para a empresa do serviço requerido (restaurante, hotel, evento cultural, etc). Por sua vez, através do operador de telemóvel, é efectivada a comunicação com a Internet e a empresa enviará a resposta para o $P D A$. Existem telemóveis com capacidades análogas aos $P D A$, pelo que podem utilizar um serviço do sistema que devolva, por exemplo, uma lista de restaurantes ou museus existentes na área onde é feita a chamada. Actualmente já existem automóveis com esta combinação de tecnologias, em breve disponíveis a custos competitivos;

- Público - através do acesso à Internet, poderá consultar os conteúdos disponíveis não classificados. Os conteúdos classificados de cada agente estarão contidos numa área reservada (Intranet), acessível aos seus clientes e fornecedores, através de uma entrada e password facultadas para o efeito. Deste modo, haverá a possibilidade de executar dentro dessa área algumas operações como reservas e transacções comerciais. Em síntese, o público é o eixo fundamental do sistema: ao navegar no website obtém-se informação variada sobre as regiões turísticas existentes em Portugal, desde a oferta de serviços e produtos de cada agente a

8 Como por exemplo, no Algarve, os quiosques multimédia do InforCid. O acesso dos multibancos ao sistema dependerá da SIBS (Sociedade Interbancária de Serviços, a qual gere as ATM).

9 Personal Digital Assistant - dispositivo portátil com funções de agenda de telefones e compromissos, bloco de notas, gestão de contactos, etc.

10 Global Positioning System - para referenciar a localização no espaço e adaptar à posição do equipamento requisitante. GPS e detecção remota são tecnologias frequentemente associadas aos SIG. 
informações genéricas sobre a cultura, história e outros atributos. É então possível organizar um pacote no qual se pode escolher o tipo de alojamento e as várias actividades para o tempo de lazer no período e na região pretendida.

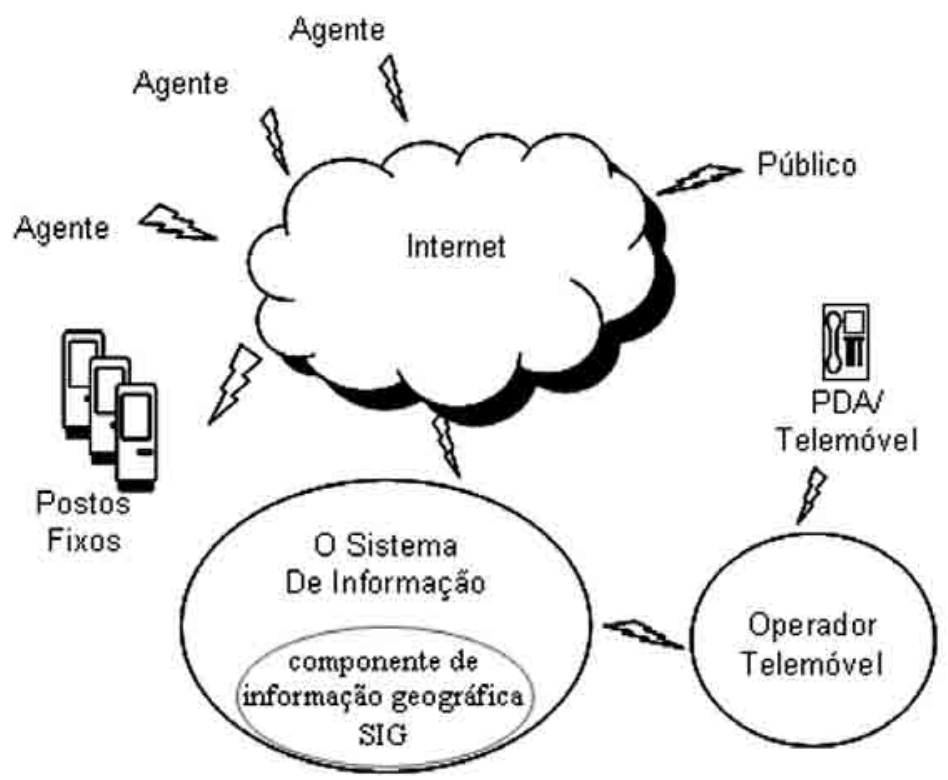

Fig. 1 - Componentes do sistema e tecnologias de suporte

Fig. 1 - System and supporting technologies components

Os visitantes do website também têm a possibilidade de, através de um processo de comércio electrónico, escolher várias formas de concretizar as suas opções. Pode ser através de um intermediário (por exemplo, uma agência de viagens que organiza e promove um conjunto de serviços de outros agentes), ou personalizando as suas opções e contactando directamente o agente. $\mathrm{O}$ sistema requer uma plataforma para a realização deste tipo de negócios que assegure fiabilidade, confidencialidade e segurança dos vários procedimentos associados a cada uma das opções. Para que a acessibilidade à informação seja maior, o sistema permite que estas funcionalidades fiquem disponíveis nos telemóveis, tirando partido das novas gerações. Uma forma inovadora será a consulta destes dados dentro do automóvel alugado pelo turista quando visita um dado país. Também existirão postos fixos em locais previamente definidos, por exemplo em aeroportos, onde os turistas poderão obter as informações disponíveis preferencialmente para a área onde estão localizados.

\section{Processos envolvidos}

O sistema de informação é composto de vários tipos de processos, em que cada um deles é requerido para executar uma tarefa específica. Um agente necessita de uma autenticação para aceder aos seus dados críticos contidos no sistema numa área reservada, 
a qual é denominada de Intranet. Nesta área poderá configurar os vários serviços e produtos de acordo com as suas políticas comerciais com cada cliente ou fornecedor. Pode criar, atribuir e remover senhas de outros agentes para acesso à sua Intranet. Caso seja útil, poderá criar um histórico das transacções comerciais ocorridas. Uma das funcionalidades principais do sistema é permitir uma gestão em tempo real das propostas de orçamentos e encomendas entre clientes e fornecedores registados no mesmo, ou entre agentes e o público. As tarefas mais complexas podem ser decompostas em procedimentos mais simples e únicos, que constituem processos em si mesmos. O conjunto de agentes económicos que prestam directa ou indirectamente serviços ao consumidor final (turista) tem a possibilidade de utilizar o sistema desde que tenha capacidade para investir em TI, pois o acesso à Internet requer computadores com a devida capacidade e software legal. Também deve ter a propensão de adaptar os seus modelos de negócio e métodos de gestão à realidade introduzida pelo sistema.

A implementação de um projecto deste tipo enfrenta várias dificuldades inerentes ao próprio ambiente onde será implantado. Como entrave ao projecto podemos considerar a elevada complexidade que o mesmo requer na fase de arranque. Nesta fase é necessário que as funções do core-business estejam implementadas, através de software desenvolvido e testado à medida, com elevada taxa de sucesso, e o sistema de comunicação e transferência de dados esteja optimizado. Ainda nesta fase é imperativo atrair grandes parceiros, que detenham uma larga percentagem do mercado, tais como operadores turísticos, agências de viagens, hotéis, etc. Isso é tanto mais difícil quanto maior quota de mercado cada parceiro detém porque, dada a sua dimensão, já tem os seus canais estabelecidos e o investimento necessário para mantê-los é inferior aos custos a suportar para "migrar" da sua plataforma para uma nova. Caso se verifique essa migração, tais parceiros perderão em larga medida o controle sobre a informação que sai de suas organizações para circular através do sistema.

Ainda na fase de lançamento, o sistema não deve permitir fugas de informação e situações de concorrência desleal entre os parceiros (assimetrias de informação). Na fase de sustentação, é esperado que o sistema encontre o seu ponto de equilíbrio económico, sob pena de uma rápida derrapagem nos custos, o que condicionaria a viabilidade económica do mesmo. Ultrapassada a fase de sustentação, bem como os principais obstáculos influenciados pela conjuntura internacional, o projecto entra na fase de maturação. O nível de operacionalidade do sistema nesta fase permite conquistar outros parceiros, de dimensão não tão significativa para o mesmo, mas que permitirão aumentar a sua performance e quota de mercado. Este cenário só é possível caso se verifique a conjugação de esforços dos vários actores e entidades envolvidas, no sentido de elevar a inovação e competitividade do sector. Aspectos políticos e não técnicos são muitas vezes a causa do insucesso pois a tecnologia, apesar das suas potencialidades, ainda não fez desaparecer as diferenças culturais. Quanto mais integração o sistema permitir, mais relações de poder são definidas na gestão da informação. Um aspecto relevante a considerar é a especificidade da cultura empresarial da região, e do sector em particular, frequentemente caracterizada por uma resistência à mudança dos métodos de trabalho e a novas formas de negócio.

\section{CONCLUSÃO}

O processo de planeamento e desenvolvimento do turismo está a tornar-se mais complexo à medida que as organizações e comunidades têm de lidar com os actuais 
desafios de sustentabilidade económica, social e ambiental. Dados espaciais e ambientais podem ser usados para explorar conflitos, examinar impactos e assistir o processo de tomada de decisão. O estudo sistemático do impacto ambiental é muitas vezes dificultado por falhas de informação, ou pela falta de ferramentas de integração, manipulação, visualização e análise dos dados. A adopção e implementação do projecto proposto contribuiria em grande medida para uma evolução dos meios tecnológicos ao dispor no turismo, permitindo a criação de serviços e produtos diferenciados, de acordo com o mercado alvo. Assim, conforme as necessidades e a localização do público-alvo, captaria um maior número de nichos de mercado.

Ao nível de uma região como o Algarve, isto será possível se o sector turístico adoptar a dinâmica requerida por uma plataforma económica e tecnológica mais integrada e eficiente, com maior capacidade de fornecer informação de forma a captar as expectativas do turista. A informação facilmente disponível e de consulta rápida e variada proporciona por sua vez novas oportunidades de negócio. A avaliação de impactos e a simulação são cada vez mais importantes no desenvolvimento do turismo e os SIG podem desempenhar um papel decisivo na auditoria de condições ambientais, na avaliação da conveniência de certas localizações e na modelização de relações. Os SIG podem ser considerados como um conjunto de ferramentas e tecnologias com uma vasta aplicabilidade na prossecução dos objectivos de desenvolvimento do turismo.

Uma das dificuldades dos agentes turísticos é a de não disporem dos tipos de informação necessários à assertividade das suas decisões quanto ao ordenamento do território. O levantamento sistemático dos recursos naturais e culturais é fundamental para a actividade turística, pois ajuda os gestores a identificar recursos disponíveis, capacidades dos locais em criar novos produtos, serviços e recursos eventualmente em risco por falta de planeamento ou pela influência de outros sectores. Os SIG permitem estudar o balanço entre áreas de acomodação turística e acomodação residencial, a fim de examinar como a ocupação varia consoante áreas menos ou mais dinâmicas e assim planear a oferta. E daí, possibilitar a análise de impactos da ocupação diferenciada do espaço, da sobrecarga à conservação, cuja tensão sobre o crescimento turístico deve ser objecto de discussão.

Um dos factores críticos na aplicação dos SIG no turismo consiste em determinar quem controla o modo como são usados e que interesses servem. A forma como os SIG são incorporados no processo de planeamento turístico pode transmitir a cultura de gestão e as relações de poder associadas. Dada a flexibilidade e alcance dos SIG, poderão ser usados para incentivar a participação dos cidadãos no planeamento turístico. Contudo, isso depende das percepções e objectivos dos diferentes agentes de política e planeamento, os quais devem entender que a perspectiva de representar e partilhar aspectos relevantes do conhecimento local é importante na formulação de políticas de desenvolvimento local. O planeamento sustentável passa cada vez mais por medidas de inovação social que assentam na partilha, negociação e compromisso entre os agentes envolvidos. Os SIG podem constituir uma ferramenta eficaz no envolvimento criativo da comunidade, permitindo um melhor conhecimento das reais necessidades de residentes e visitantes. 


\section{BIBLIOGRAFIA}

Ananthaswamy A (2004) Massive growth of ecotourism worries biologists. New Scientist Print Edition, USA.

Bahaire T, Elliot-White M (1999) The application of Geographical Information Systems (GIS) in sustainable tourism planning. A review. Journal of Sustainable Tourism, 7(2): 159-174.

Benabdallah S, Soltane K (1996) The importance of multimedia and geographical information system technologies in the tourism industry. European Research Consortium for Informatics and Mathematics, ERCIM.

Boyd S, Butler R (1996) Seeing the forest through the trees: using gis to identify potential ecotourism sites in northern ontario. In Harrison L, Husbands W (eds.) Practising Responsible Tourism: International Case Studies in Tourism Planning, Policy \& Development. John Wiley and Sons, New York: 380-403.

Buhalis D (2003) eTourism, information technology for strategic tourism management. Prentice Hall, London.

Chen R (2007) Significance and variety of Geographic Information System (GIS) applications in retail, hospitality, tourism and consumer services. Journal of Retailing and Consumer Services, 14(4): 247-248.

Colak H, Aydinoglu A (2006) Determining regional tourism development strategies of east black sea region of Turkey by GIS. Paper presented at the FIG XXIII Congress, Munich.

Correia A, Moço C (2005) Na senda da satisfação dos turistas. O caso do turismo português. In Faculdade de Economia da Universidade do Algarve (eEd.) Estudos II: 59-76.

Cowen D, Shirley W (1991) Integrated planning information systems. In Maguire D, et al. (eds.) Geographical information system: principles and applications. Longman Scientific \& Technical, London: 297-310.

Elliot-White M, Finn M (1998) Growing in sophistication: the application of GIS in post-modern marketing. Journal of Travel and Tourism Marketing, 7(1): 65-84.

Gunn C (1994) The emergence of effective tourism planning and development. In Seaton A, et al. (eds.) Tourism the state of the art. John Wiley and Sons, Chichester: 10-19.

Hadzic O (2004) Tourism and digitization of cultural heritage. Review of the National Center for Digitization Publisher, 5: 74-79.

Haines-Young R, Bunce R, Parr T (1994) Countryside information system: an information system for environmental policy development and appraisal. Geographical Systems, 1(4): 329-345.

Holm-Pedersen J (1994) GIS - a new tool for tourism. Paper presented to GIS in Business 94' European Conference, Amsterdam.

Lau G, McKercher B (2007) Understanding tourist movement patterns in a destination: a GIS approach. Tourism and Hospitality Research, 7: 39-49.

Millar D, Morrice J, Horne P, Aspinall R (1994) The use of geographic information systems for analysis of scenery in the cairngorm mountains. In Price M, Heywood D (eds.) Mountain environments and GIS. Taylor \& Francis, London: 119-132.

Poon A (1993) Tourism, technology and competitive strategies. CAB International, Oxford.

Selman P, Davidson D, Watson A, Winterbottom S (1991) GIS in rural environmental planning: visual and land-use analysis of major development proposals. Town Planning Review, 62(2): 215-223.

Wood M (2002) Ecotourism: principles, practices and policies for sustainability. UNEP Publication, in collaboration with The International Ecotourism Society. 